\title{
Effect of meteorological conditions on odour emission at biogas plants processing municipal waste - pilot research
}

\author{
Marta Wiśniewska ${ }^{1, *}$, Andrzej Kulig ${ }^{1}$, Krystyna Lelicińska-Serafin ${ }^{1}$ \\ ${ }^{1}$ Warsaw University of Technology, Faculty of Building Services, Hydro and Environmental \\ Engineering, ul. Nowowiejska 20, 00-653 Warszawa
}

\begin{abstract}
Biogas plants processing municipal waste on the one hand represent a trend in waste management, and on the other hand constitute an alternative energy source. Next to their unquestionable benefits, due to the character of the provided activity, they can be a potential source of odours. Municipal waste, largely containing biodegradable fractions, is often subject to decomposition processes in uncontrolled conditions still before it is supplied to the mechanical biological treatment plant. One of the effects of the processes, both controlled and uncontrolled conditions, is emission of odorants. Their spread depends on the applied technologies and adherence to the technological regime during operation. One of the factors determining the types and concentrations of emitted odorants are also meteorological conditions in which waste is stored and processed. The paper presents results of two series of pilot research conducted at four plants, involving a preliminary analysis of the effect of meteorological conditions on the emission of odorants at biogas plants processing municipal waste.
\end{abstract}

\section{Introduction}

The municipal solid waste has the potential for recovery of materials and energy and can be a renewable source. Waste-to-energy technologies are like a renewable energy source [1-3]. Due to the increase in the number of new mechanical biological treatment plants (MBT) in Europe (which are an indispensable part of the municipal infrastructure $[4,5]$ ), the qualitative characteristics of odour emissions from MBT plants is becoming a tool necessary for proper planning of new installations, as well as protection of health of both their operating employees and residents of the surrounding areas $[6,7]$. Such factors contributed to the publication of scientific papers presenting measurements and chemical characteristics of emissions from MBT plants [7-9]. Some of the aforementioned papers focus on the investigation of parameters that contribute to the development of unpleasant smells $[7,8]$.

Odour emissions constitute a problem due to their effect on public health through the expansion of nuisance for the population [10]. According to [11] analysing biogas plants in the Czech Republic, one of the primary types of impact on the environment is emission of pollutants, including odours. According to the authors, the primary cause of odour emission

\footnotetext{
*Corresponding author: marta.wisniewska.89@wp.pl
} 
is lack of encapsulation of technological processes, and their improper organisation. Development of odours in the processes of waste treatment, as well as their level, depend on the type of waste subject to the processes, processing methods, applied design solutions, and way of operation of the installation, including the technological regime. In addition to the aforementioned factors, meteorological conditions occurring during the collection, storage, and processing of waste are of considerable importance from the point of view of odour emission [12]. Relations between all the factors, however, are still not well-known.

Biogas plants processing municipal waste are a part of mechanical biological treatment installations. The operation of this type of biogas plants functioning in the territory of Poland is primarily based on processing of biodegradable fractions separated mechanically (by means of separators) from the mixed stream of municipal waste [12]. During its processing, process gases are released containing among others volatile organic compounds (VOC) and inorganic compounds $\left(\mathrm{H}_{2} \mathrm{~S}, \mathrm{NH}_{3}\right)$ that become a considerable source of odour nuisance in cities, and a threat to public health and safety of the natural environment [13-16]. Both the mechanical and biological part of the installation are sources of odour emissions.

The expansion of pollutants originating from surface or volumetric objects largely depends on different kinds of air movements in the atmosphere - horizontal (advection), vertical (convection), as well as gliding and waves [17, 18]. Horizontal air movement is related to the occurrence of wind, and vertical with currents occurring over heated surfaces of emission sources. The remaining air movements result from factors such as land relief or natural or artificial barriers in the form of trees or buildings [17].

An increase in wind speed results in a decrease in concentrations of compounds developing the contaminant plume $[17,19]$. In the case of low-lying sources of contaminants, the biggest concentrations of contaminants are observed in the lowest layers of air (right above the ground level). The contaminant plume has the ability of shifting in the atmosphere layer together with the surrounding air masses, adopting a speed equal to the speed of wind.

Atmospheric precipitation has a considerable effect on the range of impact of the contaminant plume through the phenomenon of absorption in rain drops, resulting in a decrease in concentrations of pollutants contained in the air (their dissolution in water) [17]. In the case of air temperature, its increase causes a spreading of pollutants, and a growth in the values of emission from the sources [17, 20].

Szulczyński et al. [21] conducted research around three sources of odour nuisance in the period from January to June. The analysis of the obtained results showed that the biggest odour concentrations were observed in summer months around each of the analysed sources. In terms of their location, the biggest odour concentrations occurred in the vicinity of the municipal landfill, followed by the vicinity of the wastewater treatment plant, and petroleum processing plant. Their research evidenced that values of mean odour concentration decrease with an increase in relative air humidity in the surroundings, which may result from the phenomenon of sorption of odour compounds on the surface and within the droplets of water vapour (water mist), causing a decrease in the odour concentration in the surrounding air. Wilson and Baieto came to similar conclusions [22].

This paper presents results of pilot research conducted at four biogas plants processing municipal waste. The objective of the paper is the determination of the relation between odour intensity and concentration and the occurring meteorological conditions (temperature and humidity of atmospheric air). The knowledge is very important from the point of view of the operation and exploitation of both the existing and future installations. Knowledge of the effect of meteorological conditions on the odour impact of waste treatment plants will permit the application of efficient operation measures minimising the odour nuisance of the installations for the surrounding areas. Papers published so far do not allow for an unambiguous, clear, and predictable assessment of the relations. This paper constitutes a substantial contribution in the issue, and opens a cycle of more extensive research aimed at 
the determination of dependencies between odour concentration and its intensity and many different factors - both meteorological and technological.

\section{Methodology}

The research covered two measurement series at four plants. It was conducted at the turn of 2018 and 2019. It involved the determination of air temperature and humidity in each designated measurement point, simultaneously controlling wind speed and direction at points located outside buildings and technological halls. Meteorological conditions were determined in the plume at a height of $1.5 \mathrm{~m}$ with the application of a Weather Meter by Kestrel. Moreover, in each point, odour intensity was determined by means of the method of sensory evaluation in a six-grade scale, where "0" means "no odour", and "5" means "very strong odour $[18,23]$, as well as $\mathrm{D} / \mathrm{T}$ parameter (dilution-to-threshold ratio) by means of a field olfactometer Nasal Ranger. Based on two readings of the parameter, odour concentration was calculated $[2,17,21]$.

Biogas plants subject to the study are located in the territory of Poland, and cover the western, southern, and eastern part of the country. Objects at which the measurements were performed are located in the following municipalities: 1 - Jarocin, 2 - Tychy, 3 - Stalowa Wola and 4 - Wólka Rokicka.

The applied technologies and adherence to the technological regime are also important elements from the viewpoint of the odour nuisance of waste treatment plants. The influence of these factors was also taken into account in the research by conducting measurements in various sources of odour emissions associated directly with the technological process. More specifically the influence of these factors was studied at biogas plants in Stalowa Wola and Wólka Rokicka and presented in the paper [22].

\section{Results and discussion}

At the examined biogas plants identified seven sources of odour emissions: 1 - the hall of waste storage, 2 - the hall of preliminary processing of waste (mechanical part), 3 - the hall of preparation of substrate for fermentation and oxygen stabilization $1^{\circ}, 4-$ the post-fermentation dewatering hall and of oxygen stabilization $1^{\circ}, 5-$ the hall of oxygen stabilization $1^{\circ}, 6$ - pile field (oxygen stabilization $2^{\circ}$ ), 7 - surface of the open biofilter. The results obtained in these sources in two measurement series are shown in Fig. 1-4.

During the pilot research at the biogas plant in Jarocin $\left(21^{\text {st }}\right.$ July 2018 and $27^{\text {th }}$ February 2019), two measurement series were performed, with considerably different mean (average) atmospheric air temperatures of $\mathrm{t} 1=30.3^{\circ} \mathrm{C}$ and $\mathrm{t} 2=11.9^{\circ} \mathrm{C}$, respectively. During the time, mean atmospheric air humidity was also variable (although to a lower degree), and equalled $\mathrm{h} 1=46.6 \%$ and $\mathrm{h} 2=69.2 \%$, respectively. Odour concentration $\mathrm{c}_{\mathrm{od}}$ in particular measurement points varied from $4 \mathrm{ou} / \mathrm{m}^{3}$ to $448 \mathrm{ou} / \mathrm{m}^{3}$ depending on the implemented technological processes. For particular measurement series, bigger odour concentrations (at particular measurement sites) were accompanied by higher atmospheric air temperature and smaller atmospheric air humidity. Such dependencies were observed at the majority of measurement sites. Odour intensity i was characterised by lower variability between the measurement series, and was to a lower degree dependent on atmospheric conditions - Fig. 2.

The pilot research at the biogas plant in Tychy ( $27^{\text {th }}$ September 2018 and $5^{\text {th }}$ March 2019) showed a considerably lower variability of meteorological conditions. Mean (average) atmospheric air humidity was at a similar level - approximately 50\%. The difference between mean atmospheric air temperature during the implementation of two measurement series was only approximately $3^{\circ} \mathrm{C}\left(\mathrm{t} 1=16.5^{\circ} \mathrm{C}\right.$ and $\mathrm{t} 2=13.8^{\circ} \mathrm{C}$, respectively). 


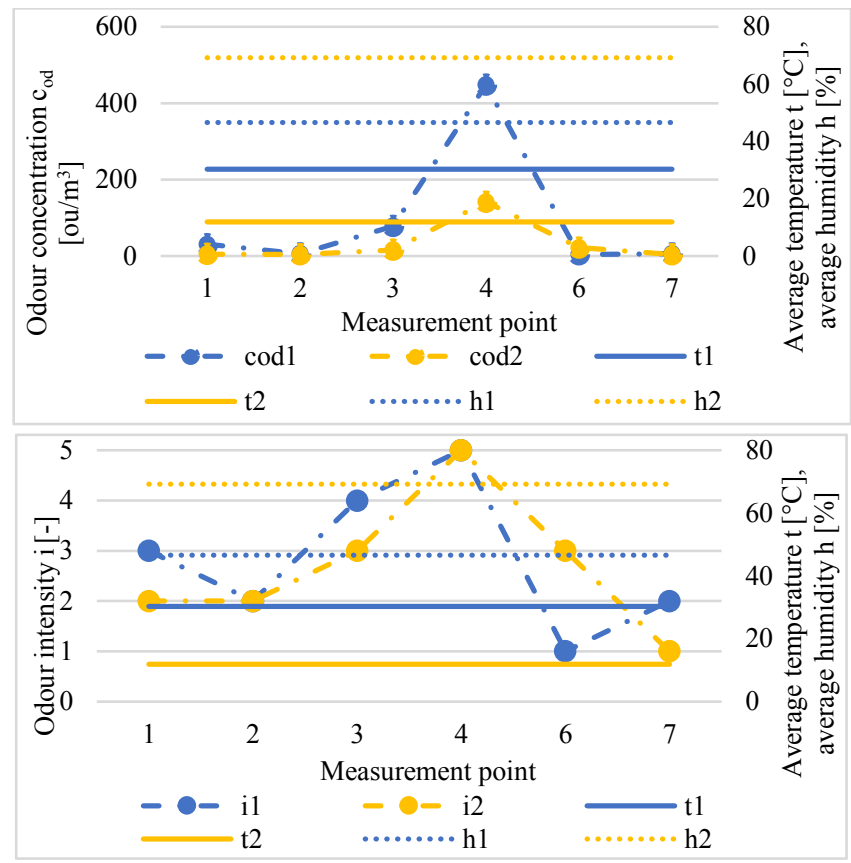

Fig. 1. Respective dependencies between odour concentration and odour intensity and average atmospheric air temperature and humidity between two measurement series at the biogas plant in Jarocin.

In spite of small differences in the scope, similar dependencies were observed between odour concentration and mean atmospheric air temperature as those recorded at the biogas plant in Jarocin. The odour concentration $c_{o d}$ was of course different in different measurement points depending on the implemented technological processes (from $3 \mathrm{ou} / \mathrm{m}^{3}$ to $42 \mathrm{ou} / \mathrm{m}^{3}$ ), but in all measurement points bigger odour concentrations (during particular research series) were accompanied by higher atmospheric air temperature. At the biogas plant in Tychy, in some measurement points, bigger (than at the biogas plant in Jarocin) variability in the scope of odour intensity was observed between particular measurement series. In this case similar dependencies were observed regarding atmospheric air temperature - Fig. 2.

The pilot research implemented at the biogas plant in Stalowa Wola (30 ${ }^{\text {th }}$ August 2018 and $20^{\text {th }}$ February 2019) showed average atmospheric air humidity at a level of approximately $50 \%$ during both measurement series. Mean (average) temperature was variable, and for particular measurement series it equalled $\mathrm{t} 1=26.1^{\circ} \mathrm{C}$ and $\mathrm{t} 2=15.0^{\circ} \mathrm{C}$, respectively. Odour concentration $\mathrm{c}_{\mathrm{od}}$ at the designated measurement sites was variable, from $4 \mathrm{ou} / \mathrm{m}^{3}$ to $78 \mathrm{ou} / \mathrm{m}^{3}$. The dependencies between odour concentration at particular measurement sites and average atmospheric air temperature were not as evident as at the biogas plants in Jarocin and Tychy. At the biogas plant in Stalowa Wola, the variability of odour concentration between particular measurement series was probably determined more by the technological properties of the processed waste and the implemented technological measures. The effect of the technological regime and the applied technologies is presented in the paper [23]. Odour intensity at the biogas plant in Stalowa Wola also depended on meteorological conditions to a lower degree than odour concentration (similarly as at the biogas plant in Jarocin) - Fig. 3. 


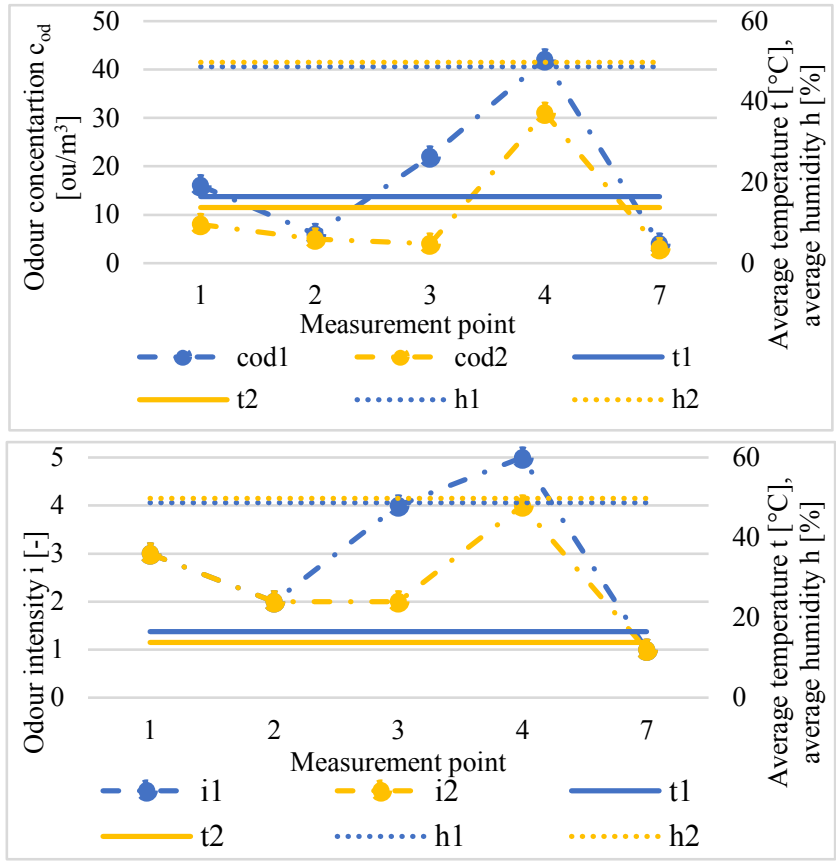

Fig. 2. Respective dependencies between odour concentration and odour intensity and average atmospheric air temperature and humidity between two measurement series at the biogas plant in Tychy.

The pilot research at the biogas plant in Wólka Rokicka (28 $8^{\text {th }}$ August 2018 and $19^{\text {th }}$ February 2019) showed a variability of mean atmospheric air temperature which equalled $\mathrm{t} 1=24.0^{\circ} \mathrm{C}$ and $\mathrm{t} 2=13.7^{\circ} \mathrm{C}$, respectively. Mean (average) atmospheric air humidity was at a level of $\mathrm{h} 1=58.9 \%$ and $\mathrm{h} 2=46.5 \%$. Odour concentration in particular measurement points was variable depending on the implemented technological processes (from $2 \mathrm{ou} / \mathrm{m}^{3}$ to $106 \mathrm{ou} / \mathrm{m}^{3}$ ). The comparison of the study results in particular measurement series reveals that bigger odour concentrations were accompanied by higher (average) atmospheric air temperature (at the majority of measurement sites - No. 1, 2, 3, and 7) - similarly as at the biogas plants in Jarocin and Tychy. Differences in average atmospheric air humidity at a level of approximately $10 \%$ had no effect on odour concentration. Odour intensity showed no differences between particular measurement series, and was less dependent on meteorological conditions (similarly as at the biogas plants in Jarocin and Stalowa Wola) Fig. 4. Summarizing, at three out of four analysed biogas plants, significant correlations were observed between odour concentration and air temperature (irrespective of differences between the temperatures in a range from $3^{\circ} \mathrm{C}$ to more than $18^{\circ} \mathrm{C}$ ). In particular measurement points, higher air temperature was accompanied by bigger odour concentrations (during separate research series). The dependencies were less evident only at one biogas plant - in Stalowa Wola. This is probably related to a greater effect of differences between technological properties of the processed waste, implemented technological measures, and observance of the technological regime at the plant, e.g. associated with encapsulation and the like (in particular research series). At the majority of analysed biogas plants, odour intensity was characterised by lower variability between the measurement series, and was less dependent on meteorological conditions. 


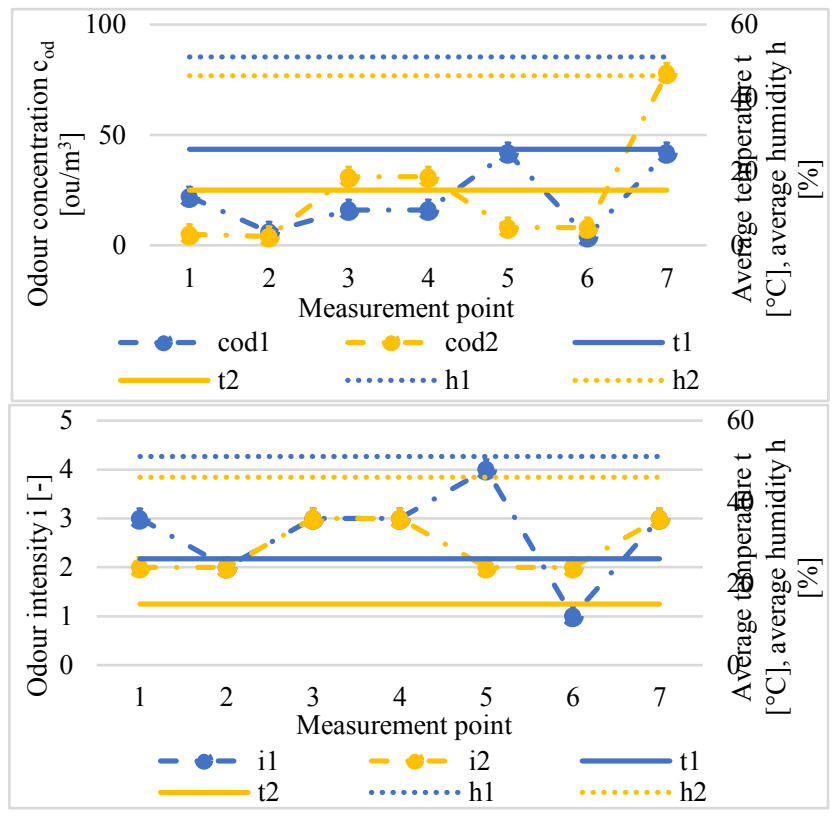

Fig. 3. Respective dependencies between odour concentration and odour intensity and average atmospheric air temperature and humidity between two measurement series at the biogas plant in Stalowa Wola.

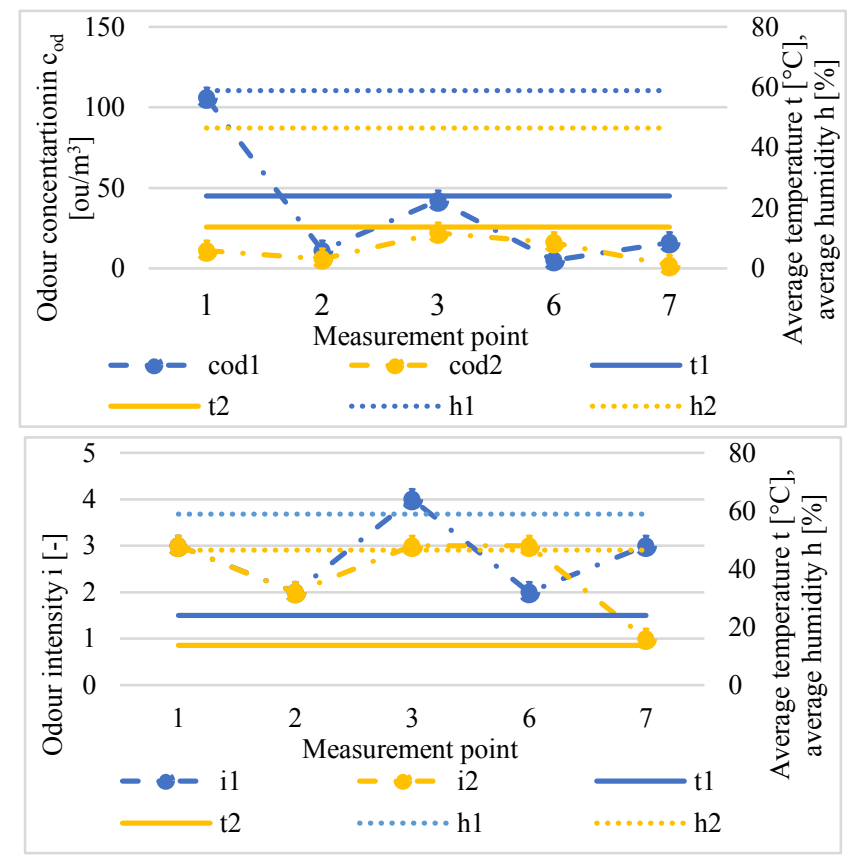

Fig. 4. Respective dependency between odour concentration and odour intensity and average atmospheric air temperature and humidity between two measurement series at the biogas plant in Wólka Rokicka. 
Only at one biogas plant - in Tychy, bigger variability of odour intensity was recorded in some measurement points ( 3 and 4 ) between particular research series. In this case, similar dependencies between odour intensity and atmospheric air temperature were observed as in the case of odour concentration - bigger odour intensity at higher atmospheric air temperature.

Results of the research show no significant effect of atmospheric air humidity on odour intensity or concentration. It is caused by smaller differences in atmospheric air humidity between particular measurement series, making drawing conclusions difficult. Only at one biogas plant - in Jarocin lower atmospheric air humidity was accompanied by bigger odour concentrations (in particular measurement points). In this case, however, differences in atmospheric air humidity between particular measurement series were recorded at a level of approximately $20 \%$. Differences in atmospheric air humidity at a level of approximately $10 \%$ had no effect on odour concentration.

The obtained results are in accordance with results presented by other authors [17, 20-22]. Knowledge on the effect of meteorological conditions on the odour impact of waste treatment plants will permit the application of effective operation measures minimising the odour nuisance of the installations for residents of the surrounding areas.

\section{Conclusion}

The paper presents results of pilot research conducted at four biogas plants processing municipal waste in Poland. It shows the relations between odour intensity and concentration and the occurring meteorological conditions (atmospheric air temperature and humidity) which can be presented at four key points:

1. At most of analysed biogas plants, significant correlations were observed between odour concentration and air temperature - higher air temperature was accompanied by bigger odour concentrations.

2. These dependencies are less visible where the applied technologies, the technological regime and the technological properties of waste exerted a greater influence on odour concentration.

3. At one analysed biogas plant similar dependencies between odour intensity and atmospheric air temperature were observed as in the case of odour concentration - bigger odour intensity at higher atmospheric air temperature. At other plants odour intensity was characterised by lower variability between the measurement series, and was less dependent on meteorological conditions.

4. At one analysed plant lower atmospheric air humidity was accompanied by bigger odour concentrations. At other plants results of the research show no significant effect of atmospheric air humidity on odour intensity or concentration. To capture the impact of air humidity, research should be conducted under more diverse atmospheric conditions.

It should be emphasised, however, that works in the scope performed to date do not allow for unambiguous, clear, and predictable assessment of the discussed dependencies. This paper constitutes the contribution in the subject. The research potential of this paper consists in conducting research in the aspect of the effect of atmospheric conditions on odour concentration and intensity in many measurement points at several mechanical biological treatment plants - both in the mechanical and biological installation, both in the conditions of the technological hall (frequently open, also affected by meteorological conditions) and in open areas.

Further works should focus on the search for relations between the technological properties of processed waste, technologies applied in its processing, technological regime, and meteorological conditions during operation. Currently, there are no comprehensive 
research in this area, but only individual analyzes. Further research should combine all these factors. This paper opens a cycle of more extensive research aimed at the determination of the dependencies between odour concentration and its intensity and many different factors related to the operation of waste treatment plants - both technological and meteorological.

\section{References}

1. S. Tan, H. Hashim, C. Lee, M. R. Taib, J. Yan, En. Pro. 61, 704-708 (2014)

2. A. Tozlu, E. Özahi, A. Abuşoğlu, Ren. Sus. En. Rev. 54, 809-815 (2016)

3. M. A. Zarea, H. Moazed, M. Ahmadmoazzam, S. Malekghasemi, N. Jaafarzadeh, Environ. Monit. Assess. 191, 131 (2019)

4. M. Wiśniewska, K. Lelicińska, E3S Web of Conferences 45, 00102 (2018)

5. M. Wiśniewska, A. Kulig, K. Lelicińska-Serafin, SHS Web of Conferences 57, 02016 (2018)

6. F. Biasioli, F. Gasperi, G. Odorizzi, E. Aprea, D. Mott, F. Marini, G. Autiero, G. Rotondo, T. D. Märk, J. Mass. Spectrom. 239, 103-109 (2004)

7. B. Scaglia, V. Orzi, A. Artola, X. Font, E. Davoli, A. Sanchez, F. Adani, Bior. Tech. 102, 4638-4645 (2011)

8. P. Pierucci, E. Porazzi, M. P.Martinez, F. Adani, C. Carati, F. M. Rubino, A. Colombi, E. Calcaterra, E. Benfenati, Chemosphere 59, 423-430 (2005)

9. S. Sironi, L. Capelli, P. Céntola, R. Del Rosso, M. Grande, Waste Manage. 27, 389-397 (2007)

10. V. Orzi, B. Scaglia, S. Lonati, C. Riva, G. Boccasile, G. L. Alborali, F. Adani, Sci. Tot. Env. 526, 116-126 (2015)

11. Lapčík, Lapčíkowá, Pol. J. Chem. Eng. 13, 3, 18-22 (2011)

12. A. Jędrczak, Biological waste treatment (Warszawa, 2012)

13. L. Capelli, S. Sironi, R. Del Rosso, P. Céntola, A. Rossi, C. Austeri, Procedia Environ. Sci. 4, 151-157 (2011)

14. V. Orzi, C. Riva, B. Scaglia, G. D'Imporzano, F. Tambone, F. Adani, Sci. Tot. Env. 621, 168-176 (2018)

15. G. De Feo, S. De Gisi, I. D. Williams, Waste Manag. 33, 4, 974-987 (2013)

16. H. Chang, Y. Zhao, H. Tan, Y. Liu, W. Lu, Sci. Tot. Env. 651, 2158-2165

17. R. Barczak, Comparative analysis of field olfactometry with other research methods in the assessment of the odour impact of sewage treatment plants (Dissertation, Warsaw University of Technology, 2014)

18. A. Kulig, Measurement and modelling based methods applicable in environmental impact assessment of municipal utilities (Warszawa, 2004)

19. Korzeniowska-Rejmer, Genorowicz, Czas. Tech. 108, 4, 113-127 (2012)

20. M. Sattler, S. Devanathan, JAWMA 57, 1296-1306 (2007)

21. B. Szulczyński., T. Dymerski, J. Gębicki, J. Namieśnik, E3S Web of Conferences 28, 01012 (2018)

22. A. D. Wilson, M. Baietto, Sensors 9, 5099-5148 (2009)

23. M. Wiśniewska, A. Kulig, K. Lelicińska-Serafin, SN Appl. Sci. 1, 550 